\title{
Utilization of Locally Made Resources in Early Childhood Education to Promote Effective Learning and Communicative Competence
}

\author{
Afoma Rosefelicia Okudo (Mrs) \\ Christy Omotuyole. (Ph.D) \\ Department of Arts and Social Sciences Education, \\ Faculty of Education, University of Lagos, Nigeria \\ Email-afomao@rocketmail.com; afomaak@gmail.com; aokudo@unilag.edu.ng
}

Doi:10.5901/ajis.2013.v2n8p13

\begin{abstract}
It has been realized by educators that the future of every society depends on laying a sound foundation for the children in early years of life. It therefore becomes imperative that appropriate and meaningful educational experiences be offered to these children. This study looked into the utilization of locally made resources in the early years of children education for effective teaching and learning and communicative competence development. Descriptive survey design was used and questionnaire was the instrument used for data collection. Five schools were randomly selected from each of the six education districts of Lagos state, Nigeria, and ten respondents were selected from each school. The population of the study comprises all the employees in all early childhood education and sample population was 300 early childhood teachers of mixed sex. Data collected were analyzed using descriptive statistics namely frequency and percentage. The study found that most of the teachers on early childhood education were not exposed to training programmes which would help to enhance their knowledge of utilizing locally made resources for teaching and learning. Recommendations were also made on how to promote the utilization of locally made resources for effective teaching ad learning and communicative competence development in preschoolers.
\end{abstract}

Keywords: locally made materials, resource utilization, early childhood education, communicative competence

\section{Introduction}

Early childhood development is regarded as the basic education on which a country may build systematically. There is every need for expansion of early childhood development activities, exploration of all available instruments of information; communication and social action, to assist people acquire the minimum basic learning necessary for a better life. It is the society that dictates the content and standards of its education and such education starts from the early years of life with its underlying goals derived from the desire to support, stimulate and guide the developmental processes of the child in the direction of competence especially communicative competence. The ultimate purpose of an effective teaching and learning is to bring about learning on the part of the learner and the symbol of learning outcome is change in behaviour which is consequential to experience (Akande, 2002). Ekwueme and Igwe (2001) asserted that it is the teacher's task to provide experiences which support, stimulate and structure children's learning to bring about a progression and understanding appropriate to the child's needs and abilities. It is therefore very important for the teacher to use teaching materials/aids to make teaching and learning simple, interesting, systematic, positively interactive and meaningful development of educational experiences especially communicative competences. Ekpo (2004) aptly declared that instructional materials are often used to compensate for the inadequacies of the sense organs or to reinforce the capacity of the dominant organs. They must be relevant for the realization of effective learning and the intentions of the curriculum.

The production of instructional materials had undergone several reviews and processes by experts from various fields. Olumorin(2009) emphasized that it is when original materials are not available for use in teaching and learning that other types and forms of instructional materials can be applied. For instance, in learning alphabets at preschool class in African setting, an imported chart with 'A' for Apple; 'B' for Balloon etc. are being used, but a locally produced chart that will reflect objects that can be easily seen in the child's environment can be used. For instance, ' $A$ ' for Ant; ' $B$ ' for Basket;' $C$ ' for Cutlass etc. It is against this background that the need to fashion out ways by which local resources to be used for developing instructional materials can be supported.

Instructional materials have been defined by various authors. Burner (1973) says that the teacher's work as 
communicator, model and identification figure can be supported by a wise use of variety of divides that expand experiences, clarify it and give it personal significance. Agun (1988) referred to instructional materials as learning materials, the proper use of which helps learners to learn faster and better. While Agina -Obu(2005) viewed it as a concrete or physical objects which provide sound, visual or both to the sense organs during teaching and learning. Hence, it is important for the development of communicative competence during the preschool years. Instructional materials will therefore include all forms of information carriers that can be used to promote and encourage effective teaching and learning activities. The instructional materials that teachers can use to improve the quality of instruction are inexhaustible. The teacher's level of resourcefulness, creativity and imagination is in fact unlimited.

Communication refers to how we interact with others and language is used to present concepts and thoughts. Many children especially preschoolers communicate successfully using non-verbal means such as signing, gestures, communication books, and communication equipment that entails locally made instructional materials. This would help children to build social relationships which provide opportunities for friendship, empathy and sharing emotions. The ability to communicate helps children to participate more fully in the society. Early exposure to toys that facilitate symbolic play and the development of children's fine motor skills has been shown to relate to receptive language skills(Tomopoulous,Dreyers,Tamis-leMonda,Flynn;Rovia\&Tineo,2006).

Communicative competence was described by Light (1997) as being able to meet the changing demands and to fulfill one's communication goal across the lifespan. For example, infants communicate primarily to express wants and needs and to develop social closeness, while school-aged children need the means and skills to meet all the four communication goals which include expressing wants and needs, developing social closeness, exchanging information, and fulfilling social etiquette routine. Similarly, locally made instructional materials should continue undergoing developmental processes until they can communicate the same goals in the early childhood education just as imported ones. Rowland and Schwiegert(2010) found that most children experienced success with as little as fifteen minutes per day of instruction with the use of locally made materials. Romski and Seveik (1997) supported that children learn language skills while using locally made materials successfully. They affirmed that the importance of locally made materials in supporting access to and progress in the general curriculum, literacy skills in particular, and effective education cannot be underestimated. Klinert et al (2002) supported that without the use of locally made instructional materials; children do not have access to effective learning which is essential to participation in the school curriculum. According to Romski and Seveik (2005), locally made instructional materials facilitate communicative competence in young children. They added that using developmental perspective, locally made instructional materials can be reviewed as a tool that aids or fosters the development of early language skills and sets the stage for later vocabulary development. Most teachers do not use them, and thereby depriving the preschoolers the benefits inherent in utilizing them. In some cases, there are no teaching aids to enhance teaching and even the teachers do not possess the skills to improvise locally made materials to enhance learning and communicative competence among the preschoolers. This study tried to find out whether utilization of locally made instructional materials has any implication for effective teaching and learning and communicative competence development in the early childhood education.

\section{Statement of Problem}

Educational activities especially in the early childhood education are based on the problems and opportunities that exist in a given environment and the materials for teaching in terms of learning experiences derived from the environment (Tomopoilous, et al, 2006). Educators have discovered that there is a subtle relationship between the effect of the environment on children and the study by children. Therefore, systematic attention should be given to creating a stimulating environment for the psychosocial development of the young children. Activities should also be tailored to the local context and should aim both to draw and to strengthen the resources available in the family and the community. Considering all the above, teaching and learning instructional materials should be used to make teaching and learning during the early childhood years simple, interesting, systematic, positively interactive and meaningful educational experiences. The value of teaching materials/aids in the educational process especially in the early year's education cannot be over-emphasized that even improvisation should be made whenever they are lacking. It has been indicated that the use of locally made materials is beneficial to the development of the early preschoolers. These materials may be available in some schools but their implications depend on the effective utilization by the teacher. In some cases they may not be available and the teacher having no knowledge of improvisation should ignore using them during teaching and learning and this will mar the efficiency of the education process and hinders the appropriate development of the child's communicative competence. When there is a short fall in the availability of instructional materials, most teachers 
are unable to improvise with what is available in their environment in order to effectively drive home lessons taught, and improve communicative competence in early childhood learners. This study therefore set out to investigate whether utilization of locally made instructional materials will help to improve effective teaching and learning and promote communicative competence development in early childhood learners.

\section{Purpose of the study}

The purpose of this study was to assess the level of utilization of locally made instructional materials in the early childhood education. Specifically the study examined the level of locally made instructional materials utilization in early childhood education in respect to the following:

1 Its implication for promoting effective teaching and learning in the early years of education.

2 Its impact on the development of communicative competence in the early childhood learners.

3 Early childhood teachers' knowledge and skills about the utilization of locally made instructional materials.

\section{Research Questions}

1. To what extent would the utilization of locally made materials help to enhance effective teaching and learning in early child hood education?

2. How does the effective implementation of available locally made instructional materials promote communicative competence among the early childhood learners?

3. To what extent do early childhood teachers posses the knowledge and skills about utilization of locally made instructional materials?

\section{Methodology}

\subsection{Research design}

This study adopted a descriptive survey research design. This method was deemed the most appropriate design for this study because it involves selecting chosen samples from a large population to discover the relative incidence distribution and interrelations of some important variables.

\subsection{Population and Sample}

The population comprised all teachers and proprietors of early childhood education in Lagos, Nigeria. In selecting the respondents, a multi-stage random sampling procedure was employed in the study. A sampling frame of all the Local Government Areas (LGAs) in Lagos was drawn and stratified into urban and rural areas. Using Probability Proportional to Size (PPS) sampling technique, two rural and four urban Local Government Areas in Lagos State were selected. A sample frame of all the registered early childhood nursery schools with Lagos State Ministry of Education was drawn from six education districts; thereafter; five schools were randomly selected from each of the six education districts to give a total number of thirty schools. In selecting the schools two criteria were considered: The schools must be registered with the Lagos State Ministry of Education and must have started their preschoolers since last three years. Nine teachers of early childhood education and a proprietor/principal each were selected from the 30 selected schools. In all, a total of 300 respondents formed the sample size.

\subsection{Instrumentation}

A Questionnaire titled Utilization of Locally Made Resources in Early Childhood Education to promote Effective Learning and Communicative Competence and a checklist constructed by the researchers was the major instrument for data collection. The questionnaire was divided into two sections: A and B. Section A contains the demographic information of the respondents while section $B$ is a close ended questions based on the Likert's 4 point scale measurement (Agreed, Strongly Agreed, Disagreed and Strongly Disagreed) with few open ended questions designed in line with the objective of the study. 


\subsection{Validation of Instruments}

The face validity of the instrument was carried out by experts/colleagues in the field of Early Childhood and Language education; thereafter a pilot study was later conducted with 50 students from a different preschool school which was not part of the study group to revalidate the instrument. With respect to reliability of the instrument, cronbach alpha method was used and the reliability yielded a coefficient of 0.80 .

\subsection{Procedure for Data Collection}

With the help of trained research assistants, the researchers administered the instruments to the subjects in their various Early childhood Nursery schools. Out of the 300 copies of questionnaire, 285 were completely filled and retrieved from the respondents for analysis giving a 95\% return rate. The questionnaire administration lasted for 4 weeks

\section{Data analysis and Discussion of Findings}

The data were analyzed with descriptive statistics involving the use of frequency counts, percentages mean and chart.

\subsection{Results}

Table: Quality of Teaching Personnel in Early Childhood Schools

\begin{tabular}{lrc} 
Qualification & F & $\%$ \\
\hline Grade II Certificate & 150 & 52.63 \\
NCE & 55 & 19.30 \\
B.ED/M.Ed & 40 & 14.04 \\
PGDE & 10 & 3.51 \\
B.Sc/B.A./M.Sc etc & 30 & 10.53 \\
Total & 285 & 100.01 \\
No of seminars/training & & \\
None & 200 & 70.18 \\
1-2times per annum & 50 & 17.54 \\
3-4 times per annum & 20 & 7.02 \\
Above 4 times per annum & 15 & 5.26 \\
Total & 285 & 100.0 \\
Experience in the present school & & \\
Less than 5 years & 150 & 52.63 \\
Between 5 and 10 years & 100 & 35.09 \\
10 years and above & 35 & 12.28 \\
Total & 285 & 100.00 \\
\hline
\end{tabular}

Keys: $N=300$

Table 1 shows the quality of teaching personnel in most early childhood nursery schools in Lagos, Nigeria. The result shows that $10.53 \%$ of the respondents have degrees and master degrees in Education, 14.04\%, B.Sc/M.Sc. Also, 3.51\% of the respondents also have postgraduate Diploma in Education while those with NCE and Grade two Certificates have $19.30 \%$ and $52.63 \%$ respectively. Similarly, with regards to number of seminars and trainings on the pedagogical improvement attended in the past two years, $70.18 \%$ of the respondents consented that they have never attended any kind of training/seminar in respect to their job in the past 3years, 17.54\% attended between 1-2times per annum, 7.02\% attended between 3-4 times while those that have attended more than four times represent only about $5.26 \%$ of the sampled population.

Finally on the question regarding the teaching experience of the respondents for the study, only $12.28 \%$ of the 
respondents have been in the job for more than 10 years, $35.09 \%$ between $5-10$ years, $12.28 \%$ of the respondents have taught for less than five years.

Table 2: Utilization of Locally Made Instruction Materials and Its Implication on school

\begin{tabular}{|c|c|c|c|c|}
\hline$F(\%)$ & & $\begin{array}{l}F(\%) \\
3\end{array}$ & $\begin{array}{l}F(\%) \\
2\end{array}$ & $\begin{array}{l}F(\%) \\
1\end{array}$ \\
\hline \multicolumn{5}{|l|}{ 1. Facilities are provided for locally } \\
\hline made instructional materials & & $\begin{array}{l}35 \\
(12.28)\end{array}$ & $\begin{array}{l}75 \\
(26.32)\end{array}$ & $\begin{array}{c}150 \\
(52.63)\end{array}$ \\
\hline $\begin{array}{l}\text { 2 Inadequate professionally trained } \\
\text { early childhood educators is a problem (12 } \\
\text { to the use of locally made instructional } \\
\text { material }\end{array}$ & $2.28)$ & $\begin{array}{l}30 \\
(10.53)\end{array}$ & $\begin{array}{l}60 \\
(21.05)\end{array}$ & $\begin{array}{l}160 \\
(56.14)\end{array}$ \\
\hline 3 Utilization of locally made instructional 18 & & $\overline{55}$ & 30 & 20 \\
\hline $\begin{array}{l}\text { materials can promote communicative } \\
\text { competence in the preschoolers }\end{array}$ & $(63.16)$ & $(19.30)$ & $(10.53)$ & $(7.02)$ \\
\hline $\begin{array}{l}\text { 4. All early childhood educators are aware that } \\
\text { locally made instructional materials }\end{array}$ & & & 15 & 10 \\
\hline $\begin{array}{l}\text { promotes teaching efficiency and leaming } \\
\text { effectiveness in the preschoolers }\end{array}$ & $(42.11)$ & $(45.61)$ & $(5.26)$ & $(3.51)$ \\
\hline $\begin{array}{l}5 \text { Early childhood teachers know that } \\
\text { locally made instructional materials } \\
\text { provide a link between the child and nature }\end{array}$ & $\begin{array}{l}115 \\
(40.35)\end{array}$ & $(50.88)$ & $\begin{array}{l}15 \\
(5.26)\end{array}$ & $\begin{array}{l}10 \\
(3.51)\end{array}$ \\
\hline $\begin{array}{l}6 \text { Financial constraint mars the use of locally } \\
\text { made instructional materials in the early } \\
\text { childhood education }\end{array}$ & $\begin{array}{c}140 \\
(49.12)\end{array}$ & $\begin{array}{l}135 \\
(47.37)\end{array}$ & $\begin{array}{l}10 \\
(3.51)\end{array}$ & $\ldots$ \\
\hline
\end{tabular}

Table 2 above presents the result of utilization of locally made instructional materials to promote effective teaching and learning and communicative competence development among the preschoolers in early childhood nursery schools in Lagos - Nigeria. The data revealed that only $8.77 \%$ of the sampled population agreed that facilities are provided for locally made instructional materials, $12.28 \%$ strongly agreed, $26.32 \%$ disagreed while $52.63 \%$ strongly disagreed with the statement. This means that teachers of early childhood education cannot carry their duties out as supposed and thus is not in agreement with Ekwueme and lgwe (2001) who asserted that it is the teacher's task to provide experiences which support, stimulate and structure children's learning to bring about a progression and understanding appropriate to the child's needs and abilities. They added that it is very important for the teacher to use teaching materials/aids to make teaching and learning simple, interesting, systematic, positively interactive and meaningful development of educational experiences especially communicative competences. Facilities are not provided for early childhood education which may impact learning and this agrees with Klinert et al (2002) who asserted that without the provision of locally made instructional materials children do not have access to effective learning which is essential to participation on the school curriculum. Similarly, with regards to the issue of training /seminars on the use of locally made instructional materials, only $12.28 \%$ of the respondents acknowledged and admitted that inadequate professional training constitute problem to the use of locally made instructional materials in the early childhood education, $10.53 \%$ strongly agreed, $21.05 \%$ disagreed while $56.14 \%$ strongly disagreed. With regards to the use of locally made instructional materials to promote communicative competence in early preschoolers, $63.16 \%$ agreed, $19.30 \%$ strongly agreed, $10.53 \%$ disagreed while 7.02\% strongly disagreed, it concurs with Romski and Seveik (2005) who emphasized that locally made instructional materials facilitate communicative competence in young children and can also be reviewed as a tool that aids or fosters the development of early language skills. Again, regarding the issue of using locally made instructional materials to promote effective teaching and learning in the early years of learnig, $42.11 \%$ agreed, $46.61 \%$ strongly agreed, $5.26 \%$ disagreed, while 5.31\% strongly disagreed and this agrees with Ekpo (2004) who aptly declared that instructional materials are often used to compensate for the inadequacies of the sense organs and that they must be relevant for the 
realization of effective learning and the intentions of the curriculum. On the issue of locally made instructional materials providing link with nature in early childhood learners,40.35\% agreed,50.88\% strongly agreed, $5.26 \%$ disagreed, while $3.51 \%$ strongly disagreed. Finally, with regards to financial constraint marring the use of locally made instructional materials, none of the respondents strongly disagreed with the statement, $3.51 \%$ disagreed, $49.12 \%$ agreed, while $43.37 \%$ strongly agreed.

\section{Recommendations}

In order to maximize educational opportunities, children who must have come to preschool with use of symbolic language should be concretized with locally made instructional materials/teaching aids. Hence, preschoolers should be taught with locally made instructional materials for them to be able to participate fully in early childhood education and also to be able to develop and achieve communicative competence that is clear, meaningful, culturally and linguistically appropriate.

There should be training and re-training of early childhood education teachers on the utilization of locally made instructional materials for the effective teaching and learning and communicative competence development of early childhood learners. This will help to promote the realization of the essence and importance of utilizing these resources.

Proprietors/head teachers should conceive the utilization of locally made instructional materials and training on how to use them as high priority activity and thus create a good opportunity for their teachers to benefit. Thus, their efforts and contribution would likely enhance /results in the effective teaching and learning and communicative competence development in the early childhood education.

\section{References}

Agina -Obu,T.N.(2005).The relevance of instructional materials in teaching and learning.In Robert Okah \& Uzoeselu,K.C.(Ed).Theory and Practice. Portharcourt. Harvey Publications.

Akande,M.O.(2002).The theory and practice of professional teacher. Lagos: Nigeria. Ekamag Publishers.

Ekwueme,L. and Igwe,R.(2001).Introduction to teaching profession. Lagos. JAS Publications.

Kleinert,H.,Garrett,B.,Towels,E.,Garrett,M.,Nowak-Drabik,K.Waddel.C.\& Kearns,J.(2002).Alternate assessment scores and life outcomes for students with significant disabilities:are they related? Assessment for Effective Intervention, 28,19-30

Light,J.C.(1997).Communication is the essence of human life: Reflections on communicative competence. Augmentative and Alternative Communicative Competence 13(2), $61-70$.

Olumorin,C.O.(2001).Preparation, production and use of visual and non-visual instructional materials and media for teaching and learning .Paper presented at Adebola College on 2-day capacity building seminar for secondary school teachers.

Romski,M.A.,\& Sevsik,R.A(2005).Augmentative communication and early intervention: myths and realities.Infants and Young Children: An interdisciplinary Journal of Special Care Practices. 18(3) $174-185$.

----(1997).Augmentative and alternative communication for children with developmental disabilities. Mental Retardation and Developmental Disabilities Research Reviews $3,363-368$.

Rowland,C.C. \& Schweigert,P.(2000).Tangibl symbols, tanglble outcomes. Augmentative and Alternative Communication Journal (2), $61-78$.

Snell,M.,Brady,N., Mclean,L.,Ogletree,B., \&Sylvester,L.(2010).Twenty years of communication intervention research with individuals who have several intellectual and developmental disabilities. American Journal on Intellectual and Developmental Disabilities 115(5), $364-380$.

Tomopoulous,S.Dreyers,B.P.,TamileMonda.C.S,Flynn,V.Rovia,I.,Tineo,W.(2000).Books,toys, parent-child iteraction and development In young Latino Children. Ambulatory Paediatrics Journal 6,72 - 78 